\title{
The Compressive Strength Characteristics of Glass Fiber Reinforced Cement Concrete with Silica Sand Material Added from Sidoarjo Lapindo Volcano Mud
}

\author{
Jafar Amiruddin ${ }^{1}$, Wildan Ananta Firdaus ${ }^{1}$, Himawan Hadi Sutrisno ${ }^{1 *}$ \\ ${ }^{1}$ Lab. Fire, Material And Safety Universitas Negeri Jakarta, Jakarta, Indonesia \\ *Corresponding author. Email: himawan-hadi@unj.ac.id
}

\begin{abstract}
This study aims to increase the economic value of silica sand originating from mud volcano of the Lapindo well burst which until now is known as a natural disaster and caused a lot of material loss by the people of Porong Sidoarjo. In addition, the replacement of the percentage of cement composition against the compressive strength of the Glass Fiber Reinforce Cement (GRC) formed will be known as the compressive strength characteristics of the concrete from the GRC made. This research was conducted using an experimental method. A mixture of cement with fiber glass and added silica sand with various compositions was used to print the research samples. The composition of cement to silica sand used has the highest ratio of 50: 50. While the lowest value of the ratio of cement and silica sand is 80:20. Next, each mixture of silica sand and cement is mixed with fiber with a fiber composition of $25 \%$ of the elements of cement and silica sand. The board molds are formed with a size of $200 \mathrm{~mm} \mathrm{X} 150 \mathrm{~mm}$ with a thickness of $10 \mathrm{~mm}$ and dried in free air until the moisture content in the mold board is reduced evenly, the moisture content of each board is measured to have a uniform value to maintain the validity of the results of the compressive strength test of GRC. Test the compressive strength of GRC using a hammer test tool, and calibration is carried out for each sample. The result of study was the greater the silica sand content in the boards that have been made, the value of the compressive strength of the concrete decreases. The best value of the compressive strength of concrete is found on the cement board which is added with silica sand as much as $120 \mathrm{mg}$. while the value of the lowest concrete compressive strength is a cement board containing a mixture of silica sand of $480 \mathrm{mg}$.
\end{abstract}

\section{Keywords: Reinforced Cement, Silica, Volcano Mud, Glass Fiber}

\section{INTRODUCTION}

As is known, Glass fiber reinforced cement (GRC) board is an alternative that is used as a substitute for dynamic walls, where the main element of making GRC is a mixture of cement as a filler and fiber as a matrix. The use of GRC provides speed and aesthetics in building installation and the costs used are relatively cheaper. The use of fiber as a matrix in the manufacture of GRC has been stipulated in cement composite standards such as those in ASTM C 1185 and ASTM C 1186. As an effort to improve the quality of GRC boards, several researchers have attempted to reveal the effect of fiber content in the composition of the cement used [1-4].

In a study conducted by Khorami et.al [5, 6], where the glass fiber used in the manufacture of GRC was added another fiber from Kraft pulp derived from waste cardboard (acrylic and polypropylene fibers), giving a positive impact in increasing flexural performance. In addition to the fiber used will affect the mechanical properties of the GRC, the shape of the fiber used also has a significant effect. It was revealed by Cakir et.al [7] that the fiber used in the chopped form has different mechanical characteristics with the fiber used in the basalt form.

While the study about the other elements addition in the manufacture of GRC, has also been investigated by Cheng et.al [3], where the GRC made with the addition of fly ash or slag elements affects the degradations mechanism. The addition of fly ash or slag improves the corrosion properties of GRC for the long term, where in his research, after 360 days of GRC, the addition of fly ash 
or slag only experienced corrosion, while at 180 days the corrosion of this material had not been significantly corroded. However, the addition of fly ash or slag did not change the crack resistance that occurred in GRC. So that the toughness degradation after the addition of fly ash or slag does not occur significantly. Like the addition of fly ash or slag, the addition of silica in the GRC also has an impact in the form of improving mechanical analysis. From the added GRC, the addition of 5\% Nano silica to the filler composition will increase $16.25 \%$ bending resistance. However, if Nano silica is added up to $7 \%$ the bending resistance actually decreases along with the addition of the percentage. However, this is inversely proportional to the thermal resistance of the GRC, where the addition of silica up to $7 \%$ of the thermal capacity of this composite increases [8]. The excessive addition of silica composition does not necessarily increase the mechanical properties of GRC. This is proven by Hamzeh et.al [9]. Where in the manufacture of fiber cement board which has a filler composition of the matrix in the form of fiber are 75:25, and the amount of cement used is replaced with a number of silica with a percentage of $25 \%$ and $50 \%$ turns out to give a significant difference. At the composition of silica and cement 50:50, the compressive strength decreases when compared to the composition of $25 \%$ silica.

Gupta et.al [10] has revealed the same thing. When $3 \%$ Nano silica is added to concrete, the effect of Nano silica is to increase work ability. In addition, it was followed by an increase in comprehensive strength of $18 \%$. So the use of Nano silica in concrete is widely recommended. If used to prevent cracking on the GRC surface, the treatment using Nano silica also has a very good impact. This is evidenced by Lee et.al [11]. Where Nano silica used for structural polymer fiber treatment on strength and interfacial toughness increased 104-113\% higher than without Nano silica treated.

In addition to providing a good effect on increasing the mechanical properties of GRC, the silica element used to coat paper is able to withstand the propagation of fire on the paper up to a certain temperature. This has been proven by the authors in the use of silica as a medium to restrain the rate of fire propagation [12]. On the other hand Silica can also be used as a material to break the fire triangle chain in several small-scale fire events and fire protection that have also been studied previously [13-18].

From the description above, silica can be used in various forms to improve the material quality. This is not only limited to building materials but also to the safety field. In addition, according to reports, elemental silica is an element that is very abundantly provided by nature. Sand, as well as foodstuffs such as rice also contain a lot of silica. In Indonesia, there is a well burst which turns out to contain a lot of silica element [19,20]. Although the well caused a lot of material loss in the area of the local population because the material that was emitted up to $100,000 \mathrm{~m} 3$ was not handled properly. So that it interferes with human life, especially in the Porong Sidoarjo area. According to the report from the disaster management agency, the material in the form of mud consists of $70 \%$ liquid and $30 \%$ solid mud, where in the mud solids there is high silica content with a percentage above $50 \%$. From this phenomenon, the authors use silica from Lapindo mud as a cement additive in the manufacture of GRC to obtain data on the compressive strength of concrete from all variations of the specimens provided.

\section{METHODS}

To find out the addition of silica as filler in the manufacture of GRC, the author uses an experimental method. To be measuring directly the compressive strength of concrete using a hammer test tool with a vertical position on each specimen that has been made. To obtain valid data, the compressive strength test of concrete tested 3 times on each specimen. This is done to eliminate the occurrence of anomalies from the hammer test tool. The filler and matrix composition of each specimen made is $85: 15$ percent where from each filler composition will be modified by adding the silica element contained in the

Lapindo mudflow. In the preparation of materials used in making GRC, cement is the most dominant element among other elements. In this study, the cement used was white Portland cement. This type of cement is different from the gray colored cement which is usually used as an ingredient for making GRC in general. The difference between white cement and gray cement can be seen in Table 1. The silica used is mild silica that has gone through the stages of filtering and heating, and then ground again to resemble powder. This is done to simplify the mixing process with cement so that it can mix perfectly. The image of silica used as a cement mixing material can be seen as shown in Figure 1. While the glass fiber used is Lloyd's type 300 glass fiber. 
Table 1. The difference of chemical elements in white cement and gray cement

\begin{tabular}{|c|c|c|c|c|c|}
\hline No & Specification & \multicolumn{2}{|c|}{ White cement } & \multicolumn{2}{|c|}{ Gray cement } \\
\hline 1 & $\begin{array}{c}\text { Morphology based } \\
\text { on SEM }\end{array}$ & \multicolumn{2}{|c|}{ 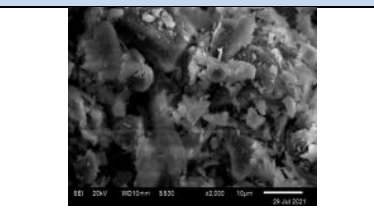 } & & \\
\hline \multirow[t]{7}{*}{2} & \multirow[t]{7}{*}{ Composition } & Element $(\mathrm{K})$ & Mass (\%) & Element $(\mathrm{K})$ & Mass (\%) \\
\hline & & C & 20.69 & $\mathrm{C}$ & 60.29 \\
\hline & & $\mathrm{O}$ & 50.11 & $\mathrm{O}$ & 22.48 \\
\hline & & $\mathrm{Mg}$ & 21.52 & $\mathrm{Al}$ & 0.25 \\
\hline & & $\mathrm{Al}$ & 0.51 & $\mathrm{Si}$ & 11.16 \\
\hline & & $\mathrm{Si}$ & 5.88 & $\mathrm{Ti}$ & 4.72 \\
\hline & & $\mathrm{Ca}$ & 1.27 & & \\
\hline
\end{tabular}

From the results of Energy Dispersive X-Ray Spectroscopy (EDS) on both types of cement, white cement has less Silica content than gray cement, so this type of cement was chosen in this study. The choice of white cement is based on the appearance of the color to be made, while the silica composition in white cement which is relatively less than the silica composition in gray cement will increase in volume along with mixing the cement with the silica sand used. While the shape of the mold used to make the specimen can be seen as shown in Figure 2.

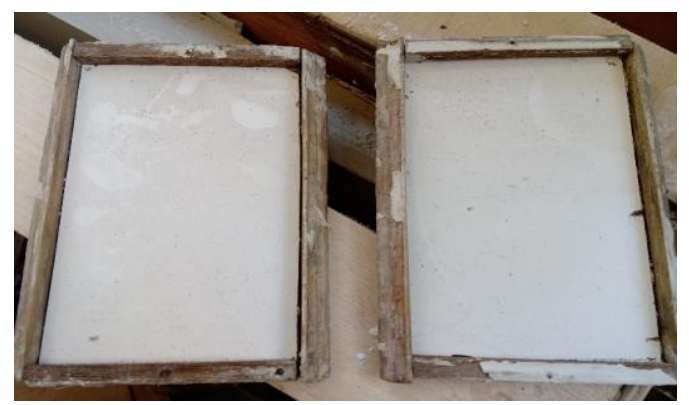

Figure 2. The mold for producing specimens

From the Table 2, the maximum fiber used is 15 from the filler in the form of a mixture of cement and silica mud, as well as the water used is weighed according to the weight of the material.

\section{RESULTS AND DISCUSSION}

Based on the tests that have been carried out, namely from the results of the study to get the even water content in each specimen requires a different time. The water content was tested using the MD4G moisture meter equipment, where the highest water con-tent in the first 24 hours was in sample 1 while the lowest water content was in specimen 5. Meanwhile, to get the ideal concrete compressive strength test results, the water content during testing was at a value the same one. For the GRC on the market has a moisture content of $13 \%$, this is in accordance with the Japanese Industrial Standard (JIS) A 5908-2003 and for other specimens the compressive 
strength test of concrete is carried out after the water content in the GRC made has reached $13 \%$. To achieve the same moisture content and be dried naturally, the drying time requirements can be seen in table 3 below.

Table 3. The drying time up to $13 \%$ of water content

\begin{tabular}{|c|c|c|c|}
\hline No & Name & $\begin{array}{c}\text { Water content, } \\
\%\end{array}$ & $\begin{array}{c}\text { Drying time, } \\
\text { hour }\end{array}$ \\
\hline 1 & Specimen 1 & 480 & 480 \\
\hline 2 & Specimen 2 & 420 & 480 \\
\hline 3 & Specimen 3 & 360 & 480 \\
\hline 4 & Specimen 4 & 330 & 480 \\
\hline 5 & Specimen 5 & 300 & 480 \\
\hline
\end{tabular}

The next one that has been produced is as shown in Figure 4. An assessment of the compressive strength of concrete using a hammer test is carried out in accordance with the ASTM 805-02 standard regarding testing the compressive strength of concrete. The results of testing the compressive strength of concrete get values like table 4. The test is carried out in a vertical position or $90 \mathrm{de}-$ grees. This is done to obtain an even position of the specimen. On each specimen, tests performed using a hammer test are carried out.

Table 4. The value of compressive strength of concrete using hammer test

\begin{tabular}{|c|c|c|}
\hline $\begin{array}{c}\text { Name of } \\
\text { specimen (\% } \\
\text { filler) }\end{array}$ & $\begin{array}{c}\text { Specimen } \\
\text { forms } \\
\text { Specimen 1 } \\
\text { (50:50) }\end{array}$ & $\begin{array}{c}\text { The average } \\
\text { value of compres- } \\
\text { sive strength of } \\
\text { concrete, Nmm }{ }^{2}\end{array}$ \\
\hline $\begin{array}{c}\text { Specimen 2 } \\
(57: 43)\end{array}$ & 10.7 \\
\hline $\begin{array}{c}\text { Specimen 3 } \\
(67: 33)\end{array}$ & & 12.0 \\
\hline
\end{tabular}

The filler composition with a ratio of cement to silica sand of 80:20 has the best compressive strength of concrete. There were conducted the tests, where from the three test results described the average compressive strength of concrete is $18.6667 \mathrm{~N} / \mathrm{mm} 2$. This is inversely proportional to the 50:50 filler composition. In this composition, silica sand is equivalent to the cement used.
From the results of the concrete compressive strength test, the value obtained is the lowest value of the $5 \mathrm{spec}$ imens provided. In other words, the composition of silica sand can result in a decrease in the compressive strength of concrete. The comparison value between the 5 specimens that have been made can be seen in the graph below. (Figure 4.).

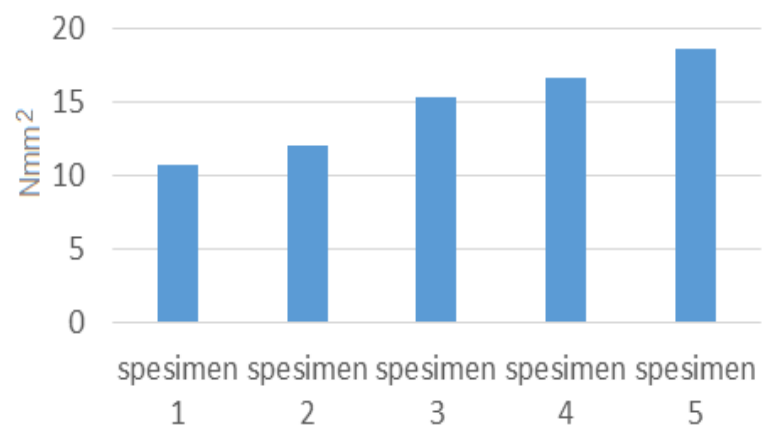

Figure 4. The value of the compressive strength of concrete in each specimen.

From the picture above, the filler composition of 57: 43 does not significantly increase the compressive strength of the concrete. This composition has the compressive strength of concrete only increases by $1.4 \mathrm{~N} / \mathrm{mm}^{2}$ from the filler composition of $50 \%$ silica sand. While the cement filler composition of silica sand 67: 33, there was an increase in the value of the compressive strength of concrete to $15,3 \mathrm{~N} / \mathrm{mm}^{2}$ where when compared to the filler composition of $50 \%$ silica sand there was an increase of $5 \mathrm{~N} / \mathrm{mm}^{2}$. The same thing happened to the filler composition 73: 27. There was an increase in the value of the compressive strength of concrete to $16,7 \mathrm{~N} / \mathrm{mm}^{2}$.

\section{CONCLUSION}

From the results of the research above, the use of silica sand as an addition to the composition of cement as a filler in the manufacture of GRC shows a negative value to the value of the compressive strength of concrete using a hammer test tool. It is evident that the compressive strength of concrete decreases with the addition of silica composition to cement. The best value of the compressive strength of concrete is obtained from the ratio of the highest cement to silica sand used. The value of the lowest compressive strength of concrete is obtained from the largest composition of silica sand to cement as filler in the manufacture of GRC board.

\section{ACKNOWLEDGMENT}

This research was funded by the BLU funds of the 
State University of Jakarta in accordance with the decision of the Chancellor of the Universitas Negeri Jakarta number 291/UN39/PT.01.02/2021.

\section{REFERENCES}

[1] A. C. Abdullah and C. C. Lee, "Effect of Treatments on Properties of Cement-fiber Bricks Utilizing Rice Husk, Corncob and Coconut Coir," Procedia Engineering, vol. 180, pp. 1266-1273, 2017.

[2] A. R. Badr, H. H. Elanwar, and S. A. Mourad, "Numerical and experimental investigation on coldformed walls sheathed by fiber cement board," Journal of Constructional Steel Research, vol. 158, pp. 366-380, 2019.

[3] C. Cheng, J. He, J. Zhang, and Y. Yang, "Study on the time-dependent mechanical properties of glass fiber reinforced cement (GRC) with fly ash or slag," Construction and Building Materials, vol. 217, pp. 128-136, 2019.

[4] K. Schabowicz, T. Gorzelańczyk, and M. Szymków, "Identification of the degree of fibre-cement boards degradation under the influence of high temperature," Automation in Construction, vol. 101, pp. 190-198, 2019.

[5] M. Khorami, E. Ganjian, A. Mortazavi, M. Saidani, A. Olubanwo, and A. Gand, "Utilisation of waste cardboard and Nano silica fume in the production of fibre cement board reinforced by glass fibres," Construction and Building Materials, vol. 152, pp. 746-755, 2017.

[6] M. Khorami, E. Ganjian, and A. Srivastav, "Feasibility Study on Production of Fiber Cement Board Using Waste Kraft Pulp in Corporation with Polypropylene and Acrylic Fibers," Materials Today: Proceedings, vol. 3, pp. 376-380, 2016.

[7] F. Cakir, "Evaluation of mechanical properties of chopped glass/basalt fibers reinforced polymer mortars," Case Studies in Construction Materials, vol. 15, p. e00612, 2021.

[8] D. F. Hincapié Rojas, P. Pineda-Gómez, and J. F. Guapacha-Flores, "Effect of silica nanoparticles on the mechanical and physical properties of fibercement boards," Journal of Building Engineering, vol. 31, p. 101332, 2020.

[9] Y. Hamzeh, K. P. Ziabari, J. Torkaman, A. Ashori, and M. Jafari, "Study on the effects of white rice husk ash and fibrous materials additions on some properties of fiber-cement composites," J Environ Manage, vol. 117, pp. 263-7, Mar 152013.

[10] M. Gupta and M. Kumar, "Effect of nano silica and coir fiber on compressive strength and abrasion resistance of Concrete," Construction and Building Materials, vol. 226, pp. 44-50, 2019.
[11] S.-J. Lee, S. Kawashima, K.-J. Kim, S.-K. Woo, and J.-P. Won, "Interfacial properties of nanosilicatreated structural polymer fibres in cement matrix composites," Composite Structures, vol. 202, pp. 465-472, 2018.

[12] H. H. Sutrisno, "The full scale fire extinguisher test for silica gel from rice husk ash," Journal of Critical Reviews, vol. 7, 2020.

[13] H. H. Sutrisno, "The selection of flying roller as an effort to increase the power of scooter-matic as the main power of centrifugal pump for fire fighter motor cycle," IOP Conference Series: Materials Science and Engineering, vol. 324, p. 012055, 2018.

[14] H. H. Sutrisno, "The Development of a Centrifugal Pump Nozzle for Firefighting Motorcycle," International Journal of Mechanical Engineering and Robotics Research, pp. 321-327, 2021.

[15] H. H. Sutrisno and Triyono, "Designing a Firefighter Motorcycle as an Effort to Provide an Early Response to Fire Disaster," Journal of Mechanical Engineering, vol. SI 4, p. 13, 2017.

[16] H. H. Sutrisno and Triyono, "Improvement of Performance and Design on Firefighter Motorcycle as a Fast Response to Decrease Fire Disaster in a Densely Populated Area," International Journal of Mechanical Engineering and Robotics Research, pp. 655-659, 2019.

[17] H. H. Sutrisno, B. Wibawa, T. Triyono, J. Amiruddin, C. S. Kusumohadi, P. Setyadi, et al., "The identification of fire potentials in oil mining area on Minas Sumatera Operations-Indonesia by manual assessment method," IOP Conference Series: Materials Science and Engineering, vol. 1098, p. 062093, 2021.

[18] H. H. Sutrisno, R. Wirawan, A. Febriani, and D. Ambarwati, "Analysis of fire rate on paper coated with the silica gel from rice husk ash," Journal of Physics: Conference Series, vol. 1402, p. 044052, 2019.

[19] H. A. Budiarti, R. N. Puspitasari, A. M. Hatta, Sekartedjo, and D. D. Risanti, "Synthesis and Characterization of TiO $2 @ \mathrm{SiO} 2$ and SiO 2 @TiO 2 Core-Shell Structure Using Lapindo Mud Extract via Sol-Gel Method," Procedia Engineering, vol. 170, pp. 65-71, 2017.

[20] A. R. Fitrianto, "Shrimp Farmers' Innovation In Coping With The Disaster (A Case Study In Sidoarjo Mud Volcano Disaster Toward Shrimp Farmers' Responses)," Procedia Economics and Finance, vol. 4, pp. 168-176, 2012. 